\title{
Educomunicação e terceiro entorno: diálogos com Galimberti, Echeverría e Martín-Barbero
}

Ismar de Oliveira Soares

Professor titular do Departamento de Comunicações e Artes da ECA/USP. Coordenador do Núcleo de Comunicação e Educação (NCE). Membro do Pontifício Conselho para as Comunicações Sociais (Vaticano 2001-2009). Coordenador do Projeto Mídias na Educação, do MEC, para o Estado de São Paulo.

E-mail: ismarolive@yahoo.com

Resumo: $O$ artigo busca novos enfoques para o entendimento da relação entre tecnologia e educação no contexto das áreas de intervenção social do emergente campo da Educomunicação. O objetivo é identificar autores que oferecem subsídios para entender a natureza das mediações que se fazem presentes a partir e em função das tecnologias, tomadas como elemento constitutivo da sociedade da informação, em que opera o agir educomunicativo. A opção pelos autores Umberto Galimberti, Javier Echeverría e Jesús Martín-Barbero permite entender como, a partir da Teoria da ação, o sujeito educomunicativo pode ambientar-se no terceiro entorno, construindo um ecossistema comunicativo aberto, democrático e participativo, superando a perspectiva funcional e instrumental pela qual as tecnologias têm sido apresentadas, vendidas e majoritariamente implantadas pelos sistemas educacionais.

Palavras-chave: tecnologias da informação, teoria da ação, terceiro entorno, ecossistema comunicativo, educomunicação.
Abstract: This paper proposes new approaches to the comprehension of the relationship between technology and education in the context of social intervention inside the emerging field of Educommunication. Its goal is to identify authors who can provide input to understand the nature of mediations that involve technologies, which are seen as constitutive elements of the information society, where the educomunicative act operates. The authors Umberto Galimberti, Javier Echeverría and Jesús Martín-Barbero allow us to understand how, from the theory of action, the educomunicative subject can fit in the third environment. According to this interpretation, an opened, communicative, democratic and participatory ecosystem is built, overcoming the functional and operational perspective in which the technologies have been introduced, sold and largely implemented by educational systems.

Keywords: information technology, theory of action, third environment, communicative ecosystem, educommunication.

É dado como certo que cada nova tecnologia cria e modifica o ambiente, levando a mudanças no modo como o homem percebe e conhece. No campo 
comunicação \& educação • Ano XV • número 3 • set/dez 2010

específico do ensino, a tecnologia tem sido vista, por uns, como mero - ainda que sofisticado - conjunto de instrumentos a serviço da didática. Para outros, apresenta-se como condição civilizatória, como uma espécie de entorno ou de ecossistema em que deveria a educação alojar-se, sob pena de fracassar em sua missão precípua de promover a aprendizagem.

Tomando estas referências como cenário de fundo, o presente artigo fará uma aproximação aos conceitos de teoria da ação, de Umberto Galimberti, terceiro entorno, de Javier Echeverría e ecossistema comunicativo, de Jesús Martín-Barbero, examinando seus fundamentos e as especificidades que possam vir a favorecer um diálogo com o conceito da educomunicação.

Um pergunta perpassará o texto: como um programa de formação, como a Licenciatura em Educomunicação, recém-criada pela Escola de Comunicações e Artes da Universidade de São Paulo (ECA-USP), deveria estar pensando sua relação com as tecnologias da informação e da comunicação?

\section{TÉCNICA E TECNOLOGIAS OU A "TEORIA DA AÇÃO"}

Para melhor entender o fenômeno em debate, trazemos para a parte introdutória deste artigo a perspectiva da teoria da ação sistematizada por Umberto Galimberti, filósofo italiano, autor de Psiche e techne, recentemente traduzido para o português ${ }^{1}$. Galimberti realiza, nas 918 páginas de seu minucioso trabalho, uma fundamentada e fecunda reflexão histórico-antropológica sobre a técnica como condição do próprio surgimento do homem enquanto ente racional. Em outras palavras, segundo ele, não teria sido a inteligência humana que criou a técnica, mas foi esta que possibilitou ao homem desenvolver sua própria racionalidade, garantindo sua sobrevivência sobre a terra ${ }^{2}$. Em síntese, o homem mantém uma dependência estreita e causal em relação à técnica.

Para chegar a esta afirmação, o autor parte do princípio de que o homem se distingue do animal não porque tenha algo a mais - a razão e a inteligência -, mas justamente porque possui algo a menos: não dispõe de institutos que o orientem, de forma direcionada, plena e absoluta, na solução de suas necessidades. Ao não encontrar em seus instintos amparo para formular respostas imediatas aos problemas da sobrevivência, o homem estaria sujeito a uma rápida e fatal extinção. Isso não ocorreu justamente porque o hiato entre necessidade e satisfação levou-o a agir. Sua satisfação - resultado de experiências com acertos e erros - permitiu o surgimento de sua capacidade de sistematizar, organizar e analisar.

Pela teoria da ação, os acertos e erros diante de uma gama enorme de estímulos e possibilidades deram ao homem a habilidade de distanciar-se das próprias necessidades imediatas (atitude não facultada aos animais), criando, para tanto, procedimentos ou técnicas que acabaram permitindo que esse ser frágil e desabilitado acabasse por dominar a terra e construir a cultura. Nesse sentido, o autor lembra que, diferentemente do animal, o organismo humano não é um aparato sensório que, por uma condição de passividade, responde 
Educomunicação e terceiro entorno - Ismar de Oliveira Soares

a determinados estímulos provenientes do mundo, mas, sim, um aparato produtivo que, agindo, determina o próprio ambiente, que nasce como resposta à sua ação. Em outros termos, a ação, ao intervir no mundo, torna possível o aparecimento daquelas situações ou daqueles objetos que não preexistem, mas são criados pela ação que o interpela ${ }^{3}$. Para Galimberti, na verdade, não há diferença entre natureza e cultura, levando em conta que, antropologicamente, a técnica - que é o elemento que possibilitou a cultura - é naturalmente constitutiva do homem. Não há homem sem técnica. Não fosse a mediação da técnica - nascida da ação -, a inteligência humana continuaria como potência, mas não se transformaria em ato, ato de refletir, de autorreconhecer-se e de solucionar problemas, de transcender.

A técnica, ao existir, se manifesta em tecnologias. Uma infinidade delas. Neste sentido, a técnica não seria apenas elemento alavancador da cultura. Seria a própria cultura, constituindo-se numa espécie de segunda natureza do homem. Sem ela o homem não se reconheceria como humano, isto é, não teria tido a oportunidade de sentir sua consciência e de se reconhecer como inteligente e racional, de produzir conhecimentos, de fazer história, de sonhar e de produzir.

Assim, quando Galimberti fala da técnica como segunda natureza, não está se referindo exatamente ao que hoje denominamos comumente de tecnologias, isto é, de artefatos, do aparentemente mais simples (a roda) ao mais complexo (o mundo digital e suas constantes autossuperações). Ele alude ao conjunto dos dispositivos através dos quais o homem busca encontrar soluções para suas demandas ou para os problemas que a vida lhe propõe.

No caso, um dado arcabouço teórico ou filosófico, como a própria ciência, por aquilo que representa em termos de mobilização humana, é entendido por Galimberti - como uma técnica. Registra, assim, a condição de dependência do homem com relação ao seu fazer. É porque ele faz que é inteligente. As tecnologias, como subprodutos da técnica, ganham, assim, nova dimensão, representando a evolução ou o retrocesso do modo de o homem estar no mundo.

O chamado progresso, fruto das tecnologias, como todos sabemos, não traz só evolução, mas pode trazer também o retrocesso! Todos testemunhamos como as tecnologias acabaram, em alguns casos, saindo do controle de seus criadores, ganhando autonomia sobre o próprio homem, sufocando-o, subordinando-o sob a forma de ideologias. Quanto mais se complexifica um aparato técnico, quanto mais se entrelaça com outros aparatos, quanto mais se agigantam os seus efeitos, mais se reduz a nossa capacidade de perceber os processos, os efeitos, os resultados e, se o pretendêssemos, os objetivos, de que somos partes e condições. Essa defasagem entre produção técnica, de um lado, e imaginação e percepção humana, do outro, torna, em não poucas vezes, o nosso sentimento inadequado em relação às nossas ações que, a serviço da técnica, produzem algo de desmesurado, a ponto de tornar nosso sentimento incapaz de reagir.

Nasce, então, segundo Galimberti, esse niilismo passivo denunciado por Nietzsche, que brota do fato de que o muito grande nos deixa frios, como que estáticos na soleira daquilo que não conseguimos abranger em nossa mente. E, 
comunicação \& educação • Ano XV • número 3 • set/dez 2010

assim, como analfabetos emotivos, assistimos, por exemplo, sem maiores perturbações de nosso espírito, à proliferação das armas nucleares e à destruição do sistema ecológico, aceitando como natural a simultânea convivência entre uma imensa riqueza de pouquíssimos ao lado de uma pobreza extrema generalizada. Todas, calamidades decididas mais pelas técnicas que regulam o regime econômico, naturalizando seus procedimentos, do que pelo efeito intencional de decisões de lideranças ou grupos de indivíduos ${ }^{4}$.

Em outras palavras, as tecnologias - uma vez implantadas e tornadas indispensáveis ao progresso alcançado - acabam por tornar plausíveis procedimentos autodestrutivos, demonstrando a necessidade da reinvenção da técnica para dar sentido à tecnologia, garantindo, assim, o retorno à capacidade de análise, de previsão e de antecipação da realidade, pelo uso da inteligência e da racionalidade. O caso da poluição da atmosfera é um dos exemplos mais recentes do domínio das tecnologias sobre a política, instalando o pragmatismo da incapacidade de análise e de antecipação. Alerta Galimberti:

Não se pode extinguir a capacidade de antecipar, essa capacidade que os gregos haviam atribuído a Prometeu, o inventor das técnicas, cujo nome significa literalmente aquele que vê por antecipação [Pro-methéus]. É essa capacidade que diminuiu no homem de hoje, que não é mais capaz de antecipar, nem mesmo de imaginar os efeitos últimos do seu fazer. É preciso evitar que a idade da técnica marque este ponto absolutamente novo na história, e talvez irreversível, em que a pergunta não seria mais: "O que nós podemos fazer com a técnica?", mas, sim: "O que a técnica fará conosco?"

Segundo o autor, o fato de a técnica ainda não ser totalitária (quatro quintos da humanidade encontra-se excluída de seus benefícios mais visíveis) não nos deve confortar, porque o passo decisivo para o absoluto técnico, para a máquina mundial, já teria sido dado, ainda que a nossa condição sentimental não tenha ainda interiorizado esse fato ${ }^{6}$. Torna-se urgente, pois, reinventar a técnica!

A reinvenção da técnica significa a defesa da tese de que o homem é maduro o suficiente para refazer a estrada, tomando consciência - mediante a ação - da necessidade de se exercitar para o controle das tecnologias, mediante a educação e o trabalho. No caso, uma aproximação necessária ao mundo das tecnologias, em se tratando da escola, deve ir além do simples empoderamento pragmático (alfabetização digital), podendo e devendo chegar ao nível da produção de conhecimento sobre o sentido da própria tecnologia nos ambientes dados.

A obra de Galimberti tem contra si todo o pensamento filosófico clássico, assim como a ciência moderna essencialista, intransigentes na defesa do princípio que sustenta o primado da razão sobre os demais sentidos do homem, colocando-a como motor da economia e da organização social. Diante do que foi dito, seja qual for o juízo que façamos sobre o pensamento do autor italiano, algo nos interessa como ponto de reflexão: é pela ação que podemos posicionar-nos na face da terra, sendo-nos permitido ensaiar esta ação, educar para esta ação, comunicar esta ação. Este é o campo da educação, ou melhor, da educomunicação. 
Educomunicação e terceiro entorno - Ismar de Oliveira Soares

\section{O "TERCEIRO ENTORNO"}

Segundo Javier Echeverría, vários ecossistemas globais abrigam o homem e suas culturas, definindo-se como esferas de vida e de convivência. O primeiro deles é constituído pela própria natureza e pelas produções culturais que relacionam o homem a ela, permitindo àquele a introdução de ordenamentos infraestruturais e culturais a título de garantia da possibilidade de vida em comum.

É o que o filósofo denomina primeiro entorno (aquele que gira ao redor do ambiente natural, do próprio corpo do ser humano e da organização de sua vida comunitária: o clã, a família, a tribo, os costumes, os ritos, a língua, a propriedade etc.). Temos, a seguir, um segundo entorno, representado pela condição humana decorrente do denominado progresso material centrado na vida urbana. É o mundo da polis, incorporando hábitos relacionados à vida na cidade, ao mercado, ao local de trabalho, às práticas culturais, às religiões, ao exercício do poder, enfim. Já o terceiro entorno é formado pelo conjunto dos instrumentos de informação e dos meios de comunicação que permitem ao homem deslocar-se dos dois primeiros entornos. Segundo Echeverría, a convivência do homem com o terceiro tem sido possível graças a um conjunto de sete equipamentos: o telefone, o rádio, a televisão, o dinheiro eletrônico, as redes telemáticas, a multimídia e o hipertexto.

$\mathrm{O}$ autor assegura que qualquer ser humano, independentemente de sua cultura e procedência geográfica, dispõe (e seguirá dispondo) dos ambientes próprios do primeiro e do segundo entornos. No caso, a educação foi aí gerada e ainda se move nos parâmetros possibilitados por estes dois ecossistemas. No entanto, o mais significativo para a nossa época é que, progressivamente, elementos e artefatos relacionados com o terceiro entorno vêm sendo súbita e cumulativamente incorporados à nossa vida cotidiana, configurando - ou mesmo impondo - formas de relações com o mundo. É o que testemunham os telefones móveis, os cartões de crédito, os computadores pessoais, a World Wide Web, as agendas eletrônicas, a televisão digital. É importante lembrar que os três entornos (natureza, espaço urbano e ciberespaço) devem ser vistos de forma simultânea, levando em conta que o terceiro não suprime, mas se acrescenta aos espaços historicamente estabelecidos.

A classificação de Echeverría dispõe, a nosso ver, pouca substância antropológica, apresentando-se como um esquema que nos ajuda a categorizar as distintas e sucessivas situações civilizatórias. Guarda um caráter funcional, de natureza didática, que pode, contudo, facilitar a sistematização de alguns dados da realidade para que, a partir destes, definamos estratégias de ação. Funciona, no mínimo, como um mapa, uma cartografia.

Se aproximarmos Umberto Galimberti de Javier Echeverría, entenderemos, de início, que tais entornos não nos foram dados de forma natural, mas que surgiram em resposta às nossas necessidades de sobrevivência coletiva. São frutos do agir humano, numa dialética cada vez mais veloz entre vida material e vida espiritual, entre a realidade e a esperança. 
comunicação \& educação • Ano XV • número 3 • set/dez 2010

7. QUADROS, Cláudia Irene. Jornalismo público na internet: uma proposta para incentivar a democracia. Disponível em <http://s3.amazonaws. com/lcp/alaic-internet/ myfiles/Claudia\%20 Irene\%20de\%20Quadro\%20(Brasil).pdf>.

8. MARTÍN-BARBERO, Jesús. Cultura y nuevas mediaciones tecnológicas Cultura e novas mediações tecnológicas). In América Latina: otras visiones de la cultura (América Latina: outras visões sobre cultura). Bogotá: CAB, 2005.
É o que observamos ao mirar especificamente o terceiro entorno, constatando que o momento civilizatório que possibilitou o acesso à era da informação vem se movendo cada vez mais rapidamente, modificando um dos condicionantes da vida em sociedade: a comunicação. Uma mudança que chega assincronicamente, favorecendo, em primeira mão, os países do primeiro mundo, como era de esperar.

Para não poucos, a lembrança de que já estamos nele mergulhados, ou estamos às suas portas, desperta, sobretudo, uma preocupação de natureza ética, envolvendo o tema da produção e uso da informação. É o que reporta a professora brasileira Cláudia Quadros ${ }^{7}$, ao assinalar que o espanhol Javier Echeverría seria, neste tópico, menos otimista, por exemplo, que Pierre Lévy, por considerar que o ecossistema que vem sendo construído mostraria uma cidade global e desterritorializada, onde os meios de comunicação estariam exercendo influência devastadora sobre os telepolistas - cidadãos passivos da cidade virtual.

O pessimismo de Echeverría, evidenciado numa comparação entre as cidades tradicionais e o ciberespaço, leva o autor a reconhecer o papel cerceador dos teleporteiros da cidade virtual, como os gatekeepers (editores que decidem o que deve ou não fazer parte do fluxo de informação entre as pessoas). Quadros lembra que, ao lançar Los señores del aire: Telépolis y el tercer entorno (1999), o autor espanhol compara a cidade com o mundo virtual, denunciando veementemente o mercantilismo - herdado do ambiente formado no segundo entorno, apelando para a urgência de um esforço extremo em torno da necessidade da democratização das tecnologias. Enfim, uma visão apocalíptica, que aponta para uma cidade desumanizada, apesar dos avanços das tecnologias de ponta.

\section{ECOSSISTEMA COMUNICATIVO: UM NOVO TIPO DE TECNICIDADE}

O filósofo espano-colombiano Jesús Martín-Barbero tem dedicado suas últimas reflexões ao tema das tecnologias da informação. Em recente curso oferecido ao Programa de Pós-Graduação da Escola de Comunicações e Artes da Universidade de São Paulo (setembro de 2008), deteve-se especialmente na questão do sentido da tecnicidade que emerge do lugar que a cultura passou a ocupar na sociedade da informação. Para ele, o lugar da cultura na sociedade se modifica quando a mediação tecnológica da comunicação deixa de ser meramente instrumental para converter-se em estrutural, como é o caso da percepção de Echeverría sobre a materialização do terceiro entorno. Ao definir a tecnicidade como elemento estruturante da cultura, Barbero a vê como um novo objeto de reflexão e de pesquisa.

De acordo com Barbero, estamos ante um novo tipo de técnica cuja peculiaridade reside em constituir-se em ingrediente estrutural da formação de um verdadeiro ecossistema comunicativo. Ecossistema que emerge associado a uma nova economia cognitiva, que define o que é conhecimento, ao mesmo tempo que especifica os modos próprios da produção deste mesmo conhecimento ${ }^{8}$. 
Educomunicação e terceiro entorno - Ismar de Oliveira Soares

Segundo este autor, com o computador, não estamos apenas diante de uma máquina, mas de um novo tipo de tecnicidade que possibilita o processamento de informações, em que as matérias-primas são as abstrações e os símbolos, inaugurando, desta forma, uma nova relação entre o cérebro e a informação, substituindo a tradicional relação entre o corpo e a máquina. As transformações nos modos como circula o saber se apresentam como uma das mais profundas mudanças paradigmáticas que uma sociedade pode sofrer: hoje, o saber é essencialmente disperso e fragmentado, escapando ao controle e à reprodução imperantes em seus tradicionais e - até agora - legítimos lugares de circulação, como a família, a escola e as igrejas.

Barbero assume que a tecnologia da informação (aparelhos e conteúdos) converteu-se, de fato, num novo paradigma da organização da sociedade:

- está incorporada aos produtos em sua composição material.

- está incorporada aos processos de produção.

- tornou-se, ela mesma, em produto.

Nesta linha de raciocínio, a Sociedade da Informação passou a significar a colocação em marcha de um processo de interconexão em nível mundial, unindo tudo o que informacionalmente tem valor - empresas e instituições, povos e indivíduos -, ao mesmo tempo que desconecta tudo o que não tem valor por essa mesma razão. Estaríamos, assim, adiante da mais profunda reorganização dos centros de poder que emprestam valor ao que hoje entendemos como mundo.

\section{DESCONFORTO}

Podemos observar que os três autores analisados não escondem, ao final de suas argumentações, certa desilusão, chegando, em alguns momentos, a unirem-se numa indisfarçável visão apocalíptica sobre o impacto das tecnologias na vida e na ação do homem, no momento histórico em que vivemos.

Para Galimberti, por exemplo, as tecnologias - uma vez implantadas acabam por tornar plausíveis procedimentos autodestrutivos por parte de seus usuários, apontando para a urgência de uma reinvenção, capaz de imprimir um novo sentido à tecnologia, garantindo, assim, o retorno à capacidade de análise, de previsão e de antecipação da realidade, pelo uso da inteligência e da racionalidade.

A reinvenção pretendida significaria a defesa da tese de que a inteligência, produto da técnica, pode reorientá-la, pela prática da mesma razão. Refazer a estrada se faz necessário, tomando o homem consciência - mediante sua ação - da necessidade de exercitar o controle sobre as tecnologias, mediante planos de pesquisa e de trabalho. Em decorrência, uma aproximação essencial ao mundo das novidades tecnológicas, no âmbito da escola, deveria ir além do simples empoderamento pragmático (alfabetização digital), devendo chegar ao nível da produção de conhecimento sobre o sentido da própria tecnologia nos ambientes dados. 
comunicação \& educação • Ano XV • número 3 • set/dez 2010

9. BRANT, João. O lugar da educação no confronto entre colaboração e competição. In: SILVEIRA Sérgio Amadeu; PRETTO Nelson (Org.). Além das redes de colaboração: internet, diversidade cultural e tecnologias do poder. Salvador: Editora da UFBA, 2008. p. 69-74
É, igualmente, contra o desvio ético em curso, pela manipulação planetariamente planejada nos fluxos de dados, informações e conhecimentos que se investe o autor espanhol Javier Echeverría, quando, em recente Ciclo de Debates sobre "A desumanização do mundo" (promovido pela Universidade Internacional de Andaluzia), denuncia os senhores do ar. Nesta ocasião, o pensador apresentou o terceiro entorno como um fenômeno representacional e multicrônico, trazendo evidentes benefícios para a sociedade, como a comunicação a distância rompendo com as noções da territorialidade, ou mesmo a ação em rede, na defesa dos interesses coletivos. Denunciou, contudo, a tendência já estabelecida - e de certa forma legitimada - ao controle planetário, dando nomes aos protagonistas: diferentemente do que sucede com o segundo entorno, os controladores não são exatamente os estados, nem instituições públicas transnacionais, potencialmente sob controle da sociedade, mas grandes multinacionais, como a Microsoft, a Intel, a Dell, a Sony e a Telefónica, que impõem aos estados e aos consumidores regras que atendem maiormente os próprios interesses, deixando a sociedade refém de suas tramas.

Diante desta realidade incômoda, Javier Echeverría recorda que não é a tecnologia em si que gera este novo espaço, mas as atitudes subjetivas e as decisões do ser humano, no contexto da luta pelo controle dos mercados cuja existência o terceiro entorno possibilitou. Para garantir a humanização do mundo digital, o filósofo fala da necessidade de criação de um contrapoder civil que faça frente ao crescente controle que os senhores do ar se atribuíram pela força de seu capital e pela inteligência estratégica de suas alianças.

Barbero entra no debate apontando para a necessidade de se desfazer um mal-entendido: a dita defesa da propriedade intelectual, sustentação jurídica da visão privatista (não coletiva) dos senhores do ar, colide frontalmente com as potencialidades abertas pelas próprias tecnologias informáticas, exigindo dos juristas, engenheiros de sistema, criadores e gestores, políticos e teóricos da informática um esforço de análise e de imaginação capaz de elaborar novas formas de regulação democrática que salvaguardem as múltiplas modalidades de direitos de autor, sem confundi-los com a trama urdida para manter o controle sobre a saúde da informação mundial nas mãos de conglomerados econômicos monopolistas. Isso não se faz sem que a sociedade tome conhecimento dos próprios direitos na sociedade do terceiro entorno e, ao mesmo tempo, esteja ciente do perigo que corre nas mãos dos grupos de poder. Aqui entra o papel da educação, ou, como defendemos, da educomunicação.

\section{O EMBATE CHEGA À ESCOLA PÚBLICA}

A preocupação de Echeverría com os senhores do ar controlando o que Barbero identifica com o ecossitema comunicativo, coloca-nos o problema da lógica do mercado, subjacente às políticas que definem o lugar da educação no confronto entre o reconhecimento da liberdade na construção do conhecimento, de um lado, e seu aprisionamento ou privatização, do outro. Segundo narra o jornalista João Brant ${ }^{9}$, a Câmara de Comércio Americana (AmCham) pôs em 
Educomunicação e terceiro entorno - Ismar de Oliveira Soares

prática, em 2007, em escolas públicas de primeiro grau do Estado de São Paulo, um projeto de alfabetização digital voltado para crianças e adolescentes de 7 a 15 anos, mediante o uso compulsório de software proprietário, com o objetivo específico de combater a denominada pirataria no uso dos recursos digitais. Em parceria com a Secretaria de Educação do Estado, os cursos miravam uma população em idade de formação de valores, que alguns anos depois adentraria a faixa etária entre 16 e 24 anos, identificada, pela indústria, com a maior consumidora de produtos piratas.

A lógica que preside as tentativas de controle sobre a internet é a da escassez, própria do jogo capitalista entre a oferta e a procura: o aprisionamento do conhecimento tornar-se-ia, no caso, condição para a sua exploração econômica. Na verdade, no caso apontado, observa-se uma tentativa de avanço da lógica competitiva, levando setores da sociedade (empresas e poder público) a caminhar numa direção oposta ao que ocorre, em um cenário mais amplo, com a sociedade civil, em que a lógica colaborativa, à qual se associa a difusão do uso do software livre, vem ganhando cada vez mais espaço. Neste sentido, na disputa entre modelos competitivos e colaborativos, a conquista da autonomia tecnológica por parte de professores e alunos, defendida pela educomunicação, passa a ter prioridade.

Segundo Brant, para entender esse cenário e entrar nesta briga em condições de estabelecer posições claras, é preciso, antes, compreender sua gramática, seus símbolos, suas regras. Por outro lado, é na própria experiência e no exercício cotidiano de relação com os meios de comunicação que a juventude se desenvolve e ganha autonomia.

\section{TRÊS PROPOSTAS}

Ante o exposto, apresentamos, à guisa de conclusão, três propostas a serem consideradas pelos programas voltados à formação de especialistas em educomunicação:

$1^{\circ}$ ) Minimizar a visão simplificadora que cerca o marketing em torno às tecnologias, tomando-as como um bem em si mesmas, lembrando que sua eficácia está na dependência das políticas e nas metodologias que definem as modalidades de seu emprego.

$2^{\circ}$ ) Garantir ao uso da técnica o caráter de ação pedagógica integradora, mediante o exercício democrático do uso dos recursos da informação, visando formar um educomunicador consciente de sua função como articulador de relações comunicativas mediadas pelas tecnologias.

$3^{\circ}$ ) Identificar nos espaços das ciências humanas os referenciais que possam ajudar a entender o fenômeno representado pelas tecnologias. No caso, espera-se que o educomunicador, mais que um tecnólogo performático, seja um gestor de processos comunicativos a quem caberá o papel de estimular o emprego dos modernos aparatos numa perspectiva permanentemente colaborativa. 
comunicação \& educação • Ano XV • número 3 • set/dez 2010

\section{REFERÊNCIAS BIBLIOGRÁFICAS}

BRANT, João. O lugar da educação no confronto entre colaboração e competição. In: SILVEIRA. Sérgio Amadeu; PRETTO, Nelson (Org.). Além das redes de colaboração: internet, diversidade cultural e tecnologias do poder. Salvador: Editora da UFBA, 2008.

ECHEVERRÍA, Javier. Los señores del aire: telépolis y el tercer entorno (Os senhores do ar: telépolis e o terceiro entorno). Barcelona: Destino, 1999.

. Telépolis. Barcelona: Destino, 1994.

GALIMBERTI, Umberto. Psiche e techne: o homem na idade da técnica. São Paulo: Paulus, 2006.

MARTÍN-BARBERO, Jesús. Cultura y nuevas mediaciones tecnológicas (Cultura e novas mediações tecnológicas). In: América Latina: otras visiones de la cultura (América Latina: outras visões sobre a cultura). Bogotá: CAB, 2005.

SOARES, Ismar de Oliveira. A mediação tecnológica nos espaços educativos: uma perspectiva educomunicativa. Comunicação \& Educação, São Paulo: CCA-ECAUSP/Paulinas, ano XII, n. 1, jan./abr. 2007.

1996.

. Sociedade da informação ou da comunicação? São Paulo: Cidade Nova,

\section{Endereços eletrônicos}

ECHEVERRÍA, Javier. Resúmenes de las intervenciones en el Seminario I de La Deshumanización del Mundo (Resumos das intervenções no I Seminário sobre a Desumanização do Mundo). Disponível em: <http://ayp.unia.es/index. php?option=com_content\&task=view\&id=411>.

Hay que crear un contrapoder civil para reglar el control social que permitan las nuevas tecnologías (É preciso criar um contrapoder civil para regular o controle social que permita as novas tecnologias). Disponível em: $<$ http:/ /ayp. unia.es/index.php?option=com_content\&task=view\&id=418>.

QUADROS, Cláudia Irene. Jornalismo público na internet: uma proposta para incentivar a democracia. Disponível em: <http://s3.amazonaws.com/lcp/ alaicinternet/myfiles/Claudia\%20Irene\%20de\%20Quadro\%20(Brasil).pdf >. 